Council honorary clinical coordinator for part of the study period. The Clatterbridge neutron therapy research programme is managed and funded by the Medical Research Council. K R Abrams is supported by a grant from the North West Cancer Research Fund. We also thank the following clinical colleagues for their support: Mr D A Berstock, Dr A J Slater, Dr J E S Brock, Dr M A Coe, Dr B Cottier, and Dr B Jones.

1 Wambersie A, Bewley DK, Lalanne CM. Prospects for the application of fast neutrons in cancer therapy. Bull Cancer (Paris) 1986;73:546-61

2 Duncan W, Arnott SJ, Jack WJL, et al. A report of a randomized trial of $\mathrm{d}(15)+\mathrm{Be}$ neutrons compared with megavoltage $\mathrm{x}$-ray therapy of bladder cancer. Int f Radiat Oncol Biol Phys 1985;11:2043-9.

3 Duncan W, Williams JR, Kerr GR, et al. An analysis of the radiation related morbidity observed in a randomized trial of neutron therapy for bladder cancer. Int F Radiat Oncol Biol Phys 1986:12:2085-92.

+ Duncan W, Arnott SJ, Jack WJL, Orr JA, Kerr GR, Williams JR. Results of two randomised clinical trials of neutron therapy in rectal adenocarcinoma. Radiother Oncol 1987;8:191-8.

5 Batterman JJ. Results of $d+T$ fast neutron irradiation on advanced tumors of bladder and rectum. Int 7 Radiat Oncol Biol Phys 1982;8:2159-64.

6 Pointon RS, Read G, Green D. A randomised comparison of photons and 15 $\mathrm{MeV}$ neutrons for the treatment of carcinoma of the bladder. Br f Radiol 1985;58:219-24.

7 Maor MH, Gillespie BW, Peters LJ, et al. Neutron therapy in cervical cancer: results of a phase III RTOG study. Int $\mathcal{f}$ Radiat Oncol Biol Phys 1988; 14:885-9].
8 Laramore GE, Krall JM, Thomas FJ, et al. Fast neutron radiotherapy for locally advanced prostate cancer: results of an RTOG randomized study. In f Radiat Oncol Biol Phys 1985;11:1621-7.

9 Laramore GE. The cyclotron saga. BMF 1990;301:344.

10 MacDougall RH, Arnott SJ. The cyclotron saga. BMF 1990;300:1721

11 Peters LJ, Maor H, Laramore GE, et al. Review of clinical results of fast neatron therapy in the USA. In: Maruyama Y, Beach JL, Feola JM, eds. Californium-252 brachytherapy and fast neutron beam therapy. Nuclear Californium-252 brachytherapy and fast neuro
Science Applications Section $B$ 1986;2:243-60.

12 Griffin TW, Wambersie A, Laramore GE, Castro J. High LET: heavy particle Griffin TW, Wambersie A, Laramore GE, Castro J. H
trials. Int f Radiat Oncol Biol Phys 1988;14:583-92.

13 Zink S, Antoine J, Mahoney FJ. Fast neutron therapy clinical trials in the United States. Am J Clin Oncol 1989;12:277-82.

14 Griffin T, Pajak T, Laramore G, Davis L. Analysis of neutron radiotherap treatment complications. Bull Cancer (Paris) 1986;73:582-6.

15 Bonnett DE, Blake SW, Shaw JE, Bewley DK. The Clatterbridge high-energy neutron therapy facility: specification and performance. $\operatorname{Br} \mathcal{O}$ Radiol 1988;61:38-46.

16 Cox DR. Regression models and life tables (with discussion). Fournal of the Royal Statistical Society $B$ 1972;34:187-220.

17 Elashoff JD. Surviving proportional hazards. Heputology 1983:73:1031-5.

18 Pocock SJ, Hughes MD. Practical problems in interim analyses, with particular regard to estimation. Controlled Clinical Trials 1989;10: particular

19 Armitage P, Berry (i. Statistical methods in medical research. 2nd ed. Oxford: Blackwell Scientific Publications, 1987:460.

20 Fleiss JL. Statistical methods for rates and proportions. New York: John Wiley, 1981:68-75.

(Accepted I March 1991)

\title{
Allergy to penicillin: fable or fact?
}

\section{S J Surtees, M G Stockton, T W Gietzen}

\section{Abstract}

Objective-To assess whether, on the basis of one blood test, penicillin allergy might be excluded sufficiently for general practitioners to give oral penicillin to patients claiming a history of penicillin allergy.

Design-Prospective study of patients referred by general practitioners.

Setting-Outpatient allergy clinic in a district general hospital.

Patients -175 referred patients who gave a history of immediate type reaction to penicillin, of whom 144 attended as requested and 132 completed the investigations.

Main outcome measures-History and examination, serum radioallergosorbent test to phenoxymethylpenicillin and benzylpenicillin, and oral challenge with penicillin.

Results-Of 132 patients, four were confirmed to have penicillin allergy by the radioallergosorbent test and 128 had an oral penicillin challenge without ill effect.

Conclusions-Most patients who gave a history of penicillin allergy are not so allergic, and their actual allergic state should be substantiated whenever feasible. For patients reporting minor or vague reactions negative findings with a radioallergosorbent test to phenoxymethylpenicillin and benzylpenicillin provide sufficient evidence to give oral penicillin safely.

Department, District

General Hospital,

Eastbourne, East Sussex

BN21 2UD

S J Surtees, FRCPED,

consultant chemical

pathologist

M G Stockton, MB, clinical

assistant

T W Gietzen, MRCGP, clinical assistant

Correspondence to: Dr Surtees.

BMF 1991;302:1051-2 sample that does not demand any special handling or storage.

\section{Patients and methods}

We studied patients referred from local general practitioners. In many cases the referral was a recognition of the need for clarification before labelling the patient as allergic; sometimes "penicillin allergy" had been casually mentioned in the course of history taking. For a few patients treatment with penicillin was indicated and it was necessary to determine whether they were allergic or not. Patients with a classic history of skin rash after receiving ampicillin during an Epstein-Barr type of virus infection were not included.

During 1983-90 there were 175 such referrals to the allergy clinic of this hospital and 144 patients attended as requested; table I shows their sex and age range. In

TABLE I-Age and sex of patients tested for penicillin allergy

\begin{tabular}{lrrrrrrrrr}
\hline & \multicolumn{8}{c}{ Age range (years) } \\
\cline { 2 - 9 } Sex & $0-$ & $15-$ & $25-$ & $35-$ & $45-$ & $55-$ & $65-$ & $\geqslant 75$ & Total \\
\hline Male & 19 & 5 & 5 & 8 & 3 & 2 & 7 & & 49 \\
Female & 17 & 20 & 17 & 18 & 8 & 10 & 4 & 1 & 95
\end{tabular}

132 patients a history was taken, an examination was made, and findings of a radioallergosorbent test to phenoxymethylpenicillin and benzylpenicillin were determined; if the test findings were negative the patient proceeded to a penicillin challenge. This consisted of ingesting a starch capsule followed about 30 minutes later by $250 \mathrm{mg}$ oral phenoxymethylpenicillin as a white tablet. No patient was tested within three months after an alleged reaction to penicillin.

Although anaphylactic reactions are rare after oral administration of penicillin, ${ }^{23}$ full resuscitation facilities were available during the oral challenge and we observed the patients for two hours afterwards and requested them to report any late reaction. 
The IgE and radioallergosorbent test methods changed during the study; all results were confirmed by the department of immunology, Royal Hallamshire Hospital, Sheffield.

Of 43 patients who did not complete the investigations, 31 failed to attend for a repeat clinic visit (table II); 10 refused a penicillin challenge; and in two patients, aged 3, oral challenge was deferred until they were older.

TABLE II-Age and sex of patients failing to attend for complete investigation

\begin{tabular}{lccccccccc}
\hline & \multicolumn{10}{c}{ Age range (years) } \\
\cline { 2 - 10 } Sex & $5-$ & $15-$ & $25-$ & $35-$ & $45-$ & $55-$ & $65-$ & $\geqslant 75$ & Total \\
\hline Male & 2 & 4 & 2 & 2 & 2 & & & & 12 \\
Female & & 6 & 9 & & 1 & 1 & 1 & 1 & 19 \\
\hline
\end{tabular}

\section{Results}

Of the 132 patients investigated, four had demonstrable IgE penicillin specific antibodies and did not proceed to an oral challenge with penicillin. Three were women aged 19, 45, and 60 respectively (cases 1-3), and one was a man aged 70 (case 4 ). One woman (case 1) gave a history of "a reaction to penicillin when aged 2," and her serum total IgE concentration was greater than $2400 \mu \mathrm{g} / \mathrm{l}$; another (case 2) gave a similar history and had a serum total IgE concentration of 223 $\mu \mathrm{g} / \mathrm{l}$; and the third (case 3 ) (serum total IgE concentration $660 \mu \mathrm{g} / \mathrm{l}$ ) gave a rambling history of reactions to drugs including penicillin and lignocaine. The fourth patient (case 4) (serum total IgE concentration $>2400$ $\mu \mathrm{g} / \mathrm{l})$ had developed urticaria after having received cofluampicil (Magnapen) for leg ulcers. The remaining 128 patients were given oral penicillin with no ill effects.

\section{Discussion}

It is accepted that penicillin allergy is overdiagnosed and that $10 \%$ of hospital patients give some record of a reaction to penicillin. ${ }^{+}$One of us (SJS) has run an allergy clinic for over 20 years, to which patients who claim they are allergic to penicillin are sometimes referred. Their story is commonly of a childhood episode when, after penicillin had been prescribed, a rash or headache developed and the doctor subsequently changed the antibiotic in case the patient was allergic to penicillin: a reasonable precaution, although the symptoms probably stemmed from the infection. This story had always been mentioned to any doctor subsequently, and none had been prepared to prescribe penicillin, again a reasonable precaution.

For some patients the spectre of penicillin allergy has deprived them of an otherwise desired treatment." The usual skin tests, using major determinants (benzylpenicilloyl polylysine) and minor determinants (benzylpenicillin) of penicillin allergy as prick and intradermal procedures, are not feasible in general practitioners' surgeries, especially as the intradermal tests carry a small but definite risk of severe reactions. Skin tests using major and minor determinants correlate well with radioallergosorbent tests with benzylpenicilloyl and phenoxymethylpenicilloyl, and significant allergy may be reliably excluded or confirmed by using both tests. ${ }^{89}$

The recurrence of symptoms when a drug is readministered provides the best evidence of a causal relation. ${ }^{10}$ The patient's agreement is essential, and drug challenges are contraindicated if a progressive response may occur. Giving a patient the drug with no subsequent adverse reaction is a most effective form of reassurance, but standard resuscitation services must be available during a challenge; which, for practical purposes, will be in hospital. Five of the patients with a negative challenge result subsequently had oral penicillin and one had intramuscular treatment, without any ill effect. General practitioners are advised to prescribe oral penicillin and, if available, to choose a colourless formulation. ${ }^{11}$

There is no absolutely reliable approach to identifying patients at risk of penicillin allergy: a patient might become sensitised by recent treatment; conversely, even when there is a recorded history of penicillin allergy, adults whose reaction occurred many years ago may no longer be allergic, ${ }^{12}$ although in most cases the history (while well intentioned) is at fault. In view of the high incidence of a history of penicillin allergy it is important that spurious "allergies" are properly discounted with the minimum of time and effort. The serum radioallergosorbent test to phenoxymethylpenicillin and benzylpenicillin is convenient, safe, and useful as a first line investigation for reactions mediated by $\operatorname{IgE}$ antibody. We caution general practitioners not to test within three months after a penicillin reaction and to apply the approach critically to patients who have a recorded history of anaphylactoid or urticarial reactions. A few patients may need to be convinced of their non-allergic state by an oral penicillin challenge at a clinic, to satisfy them that they have received a dose similar to that which might be prescribed by their general practitioner.

We thank Dr A Milford Ward of the Supraregional Protein Reference Unit, Sheffield, and Mr P R Eaton for their valued help, and Miss G E Stickler for clerical help.

1 Pearce SJ. Adverse effects of drugs on the lung. Adverse Drug Reaction Bulletin 1982:94:344-5.

2 Fox AM. Anaphylactoid shock induced by oral penicillin and resulting in Gerstmann's syndrome. BMF 1965;ii:206-8.

3 Simmonds J. Hodges $S$, Nicol $F$, Barnett D. Anaphylaxis after oral penicillin. BMJ 1978;ii: 1404 .

4 Sorensen HT, Kjaerulff E. Is type I penicillin allergy overdiagnosed in children? Scand f Prim Health Care 1986:4:252-3.

5 Oswald NTA. Penicillin allergy: a suspect label. BMF 1983;287:265-6.

6 Kirk CR, Dorgan JC, Hart CA. Gas gangrene: a cautionary tale. BMJ 1988;296:1236-7

7 Beeley L. Allergy to penicillin. BMF 1984;288:511-2.

8 Jarisch R, Roth A. Boltz. A, Sandor L. Diagnosis of penicillin allergy by mean of Phadebas RAST penicilloyl $\mathrm{G}$ and $\mathrm{V}$ and skin tests. Clin Allergy 1981;11 155-60.

9 Chandra RK, Joglekar SA, Tomas E. Penicillin allergy: anti-penicillin IgE antibodies and immediate hypersensitivity skin reactions employing major and minor determinants of penicillin. Arch Dis Child 1980;55:857-60.

10 Smith AG. Cutaneous adverse reactions to systemic drug therapv. Adverse Drug Reaction Bulletin 1989;134:500-3.

11 Myers PC. An unusual measure to prevent an adverse drug reaction. BMY 1989;291:450.
1980

12 Holgate ST. Penicillin allergy: how to diagnose and when to treat. BMJ 1988;296:1213-4.

(Accepted 5.March 1991) 